\title{
Survival after initial hospitalisation for heart failure: a multilevel analysis of patients in Swedish acute care hospitals
}

\author{
J Merlo, P-O Östergren, K Broms, A Bjorck-Linné, H Liedholm
}

Department of

Community Medicine, Malmö University

Hospital, Lund

University, Malmö,

Sweden

J Merlo

P-O Östergren

A Bjorck-Linné

H Liedholm

The NEPI Foundation, Medical Research Centre, Malmö,

Sweden

J Merlo

Department of Cardiology, Malmö University Hospital, Lund University, Malmö, Sweden

K Broms

Correspondence to: Dr Merlo, Department of Community Medicine Malmö University, Hospital, S-205 02 Malmö, Sweden (Juan.Merlo@smi.mas.lu.se)

Accepted for publication 4 December 2000

\begin{abstract}
Study objective-Although national variation in short-term prognosis (that is, 30 day mortality) after a patient's first hospitalisation for heart failure may depend on individual differences between patients, dissimilarities in hospital practices may also influence prognosis. This study, therefore, sought to disentangle patient determinants from institutional factors that might explain such variation.

Design-A multilevel logistic regression modelling was performed with patients (1st level) nested in hospitals (2nd level). Institutional effects (that is, 2nd level variance and intra-hospital correlation) were calculated unadjusted and adjusted for specific patient (that is, age and previous diseases) and institutional (that is, size of hospital) characteristics. Patients were followed up until death or 30 days from hospital admission.

Setting-Hospitals in Sweden.

Patients-The study identified all the 20420 men and 17923 women (ages 65 to 85 ) admitted to the 90 acute care hospitals in Sweden during the period 1992-1995 for their first hospitalisation attributable to heart failure.

Main results-Patient age and previous diseases (particularly senile dementia) were major determinants of impaired prognosis. Institutional factors explained only $1.6 \%$ and $2.3 \%$ of the total variation in 30 day mortality in men and women, respectively. These modest institutional effects remained after adjusting for patient age and previous diseases, but were in part explained by hospital size.

Conclusions-National variation in shortterm prognosis after an initial hospitalisation for heart failure was mainly explained by differences between patients, with hospital factors playing a minor part. Of the latter, hospital size seemed to emerge as one determinant (that is, the greater the number of patients, the better the individual prognosis).

(f Epidemiol Community Health 2001;55:323-329)
\end{abstract}

Heart failure is a public health problem whose growth is expected to increase during the coming years. ${ }^{1}$ As there are differences between hospitals in the prognosis of patients with heart failure, and in Sweden the principle of equity is a cornerstone of the health care system, ${ }^{2}$ accurate epidemiological monitoring is desirable to understand these differences. Nevertheless, evaluations performed by conventional single level analytical methodologies have been seriously criticised, ${ }^{3-8}$ primarily because they fail to consider the existence of a multilevel structure when analysing a patient's prognosis in different hospitals (that is, patients nested in hospitals). Single level analyses underestimate statistical uncertainty and lead to inappropriate ranking, which may in turn mislead public opinion and provide an unsuitable basis for decision making. ${ }^{34}$ Moreover, these single level analyses are unable to discern whether the observed variation in prognosis is attributable to individual differences between patients, or to the influence of institutional or contextual factors related to the hospitals (for example, a hospital's practice). ${ }^{3}$ Multilevel analysis is today considered a more appropriate way to monitor health care performance, as it allows a less biased estimation of uncertainty, and can also separate and quantify contextual (in contast with individual) effects. ${ }^{3-8}$ We sought, therefore, to apply multilevel analysis in order to arrive at the determinants of short-term prognosis for patients in Swedish acute care facilities experiencing their first hospitalisation for heart failure.

\section{Methods}

STUDY POPULATION

The country of Sweden is the northernmost part of the European Union. By December 1995, the total population of Sweden was 8594124 inhabitants. According to information from the National Patient Register and from Statistics Sweden, 4.0\% (4428/603 941) of the men and $2.3 \%$ (17 923/790 078) of the women aged 65 to 85 years were discharged at least once from the 90 Swedish acute care hospitals with a primary diagnosis of heart failure by ICD-9 (International Classification of Diseases, 9th ed) code 428, between 1 January 1992 and 31 November 1995. These patients, who constituted the study population, were considered first time hospitalised for heart failure as none of them had been hospitalised for this condition since at least 1987.

The National Patient Register includes information on every Swedish hospital by identification code, and records the age, gender, admission and discharge dates, as well as the primary and secondary diagnoses of all patients. Information on the vital status (that is, death) of every resident in Sweden is recorded in the National Mortality Register. A unique 10 digit personal identification number, assigned 


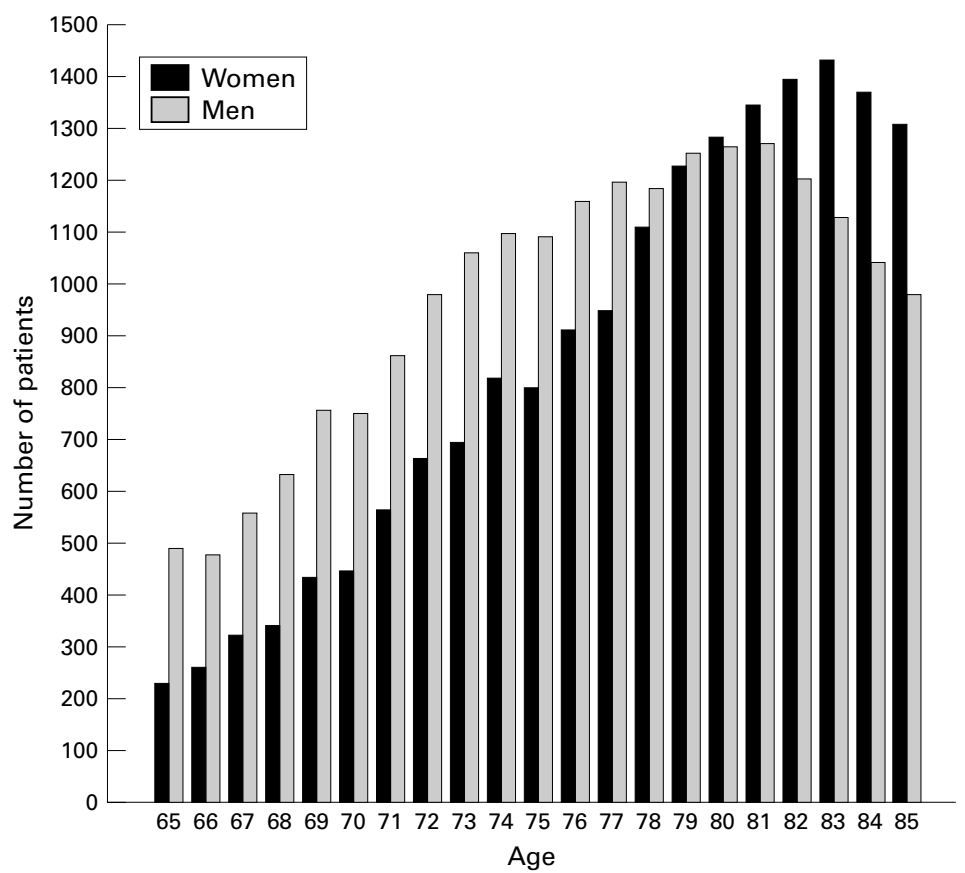

Figure 1 Number of patients 65-85 arranged according to age at the time of their first hospital admission for heart failure. Information taken from the Swedish National Patient Register (1992-1995). tradition of administering health care registers. Such registers are audited regularly, as they form the basis for resource allocation and community health surveys. Moreover, the existence of a centralised national registry limits the risk of differential information bias that might affect findings if locally based (for example, county) registers were used. ${ }^{9}$

\section{OPERATIONAL DEFINITIONS}

Short-time prognosis was defined by the vital status of the patient within 30 days from admission to the hospital. Age was computed from a patient's birth up to first admission for heart failure. For both men and women, age was categorised into five groups by quintiles, with the first being used as a baseline for reference in the comparisons. Previous cancer was defined as at least one discharge diagnosis before that patient's first hospitalisation for heart failure according to ICD-9 codes 140195. Similarly, previous infectious disease was defined by codes 001-139, previous endocrinological, nutritional, metabolic disease, or immunity disorder by codes 240-279, previous cardiovascular disease by codes 390-459 (no patient had a code 428), previous senile dementia by code 290, and previous injury or poisoning by codes 800-999.

Hospital size was defined by the total number of patients of all ages with primary or secondary hospitalisation for heart failure during the period 1992-1995. Each patient was assigned the same hospital size value as other patients in the same institution. Patients were then classified into four groups by quartiles of hospital size, with the group attended at the largest hospitals serving as reference in the comparisons.

EPIDEMIOLOGICAL AND STATISTICAL METHODS As surveillance of the 30 day follow up period was completed for all patients, multilevel logistic regression was used to carry out a survival analysis. We performed a two level simple variance components modelling ${ }^{9}$ with hospitals at the 2 nd level and patients at the 1 st level. Using an empty model (that, without any independent variable), the 2 nd level (hospital) variance in prognosis was first calculated. In subsequent models, age was included, either alone (Model 2); along with previous diseases (Model 3); with the contextual variable hospital size (Model 4); or with both previous diseases and hospital size (Model 5). The 2nd level (between hospital) variance and the percentage of the total the information in a form that preserved the anonymity of the subjects. Sweden has a long

Table 1 Diagnoses of death in 4467 patients with initial hospitalisation for heart failure who died within 30 days from admission to one of the 90 Swedish acute care hospitals (period 1992-1995)

\begin{tabular}{llllll}
\hline & ICD-9 code & $\begin{array}{l}\text { Number of } \\
\text { patients }\end{array}$ & $\begin{array}{l}\text { Percentage of } \\
\text { men }\end{array}$ & $\begin{array}{l}\text { Percentage of all } \\
\text { diagnoses }\end{array}$ & $\begin{array}{l}\text { Cumulative } \\
\text { percentage }\end{array}$ \\
\hline Chronic ischaemic heart disease & 414 & 1010 & 57 & 22.6 & 22.6 \\
Acute myocardial infarction & 410 & 915 & 59 & 20.5 & 43.1 \\
Heart failure & 428 & 427 & 52 & 9.6 & 52.7 \\
Arteriosclerosis & 440 & 173 & 60 & 3.9 & 56.5 \\
Pneumonia & 486 & 127 & 55 & 2.8 & 59.4 \\
Diseases of endocardium (valve disorder) & 424 & 123 & 43 & 2.8 & 62.1 \\
Ill defined complications of heart disease & 429 & 110 & 52 & 2.5 & 64.6 \\
Old myocardial infarction & 412 & 102 & 71 & 2.3 & 66.9 \\
Arrhythmias & 427 & 100 & 45 & 2.2 & 69.1 \\
Diabetes mellitus & 250 & 83 & 55 & 1.9 & 71.0 \\
Pulmonary embolism and infarction & 415 & 51 & 59 & 1.1 & 72.1 \\
Stroke & $434-436$ & 85 & 58 & 1.9 & 74.0 \\
\hline
\end{tabular}


Table 2 Description of the population as a function of hospital size groupings and the profile of patients with a first diagnosis of heart failure in 1992-1995 attending the 90 Swedish acute care hospitals. Values are percentages if not otherwise indicated

\begin{tabular}{|c|c|c|c|c|c|c|c|c|c|c|}
\hline \multirow[b]{2}{*}{$\begin{array}{l}\text { Hospital size } \\
\text { median (min-max) }\end{array}$} & \multirow[b]{2}{*}{$\begin{array}{l}\text { Number of } \\
\text { hospitals }\end{array}$} & & \multirow[b]{2}{*}{ Mean age } & \multirow[b]{2}{*}{$\begin{array}{l}30 \text { day } \\
\text { mortality }\end{array}$} & \multicolumn{6}{|c|}{ Previous diseases } \\
\hline & & & & & $\begin{array}{l}\text { Infectious } \\
\text { diseases }\end{array}$ & Cancer & Senile dementia & $\begin{array}{l}\text { Cardiovascular } \\
\text { diseases }\end{array}$ & $\begin{array}{l}\text { Previous } \\
\text { injuries and } \\
\text { intoxications }\end{array}$ & $\begin{array}{l}\text { Other } \\
\text { diseasest }\end{array}$ \\
\hline A & & W & 77.9 & 12.0 & 4.6 & 7.0 & 0.9 & 34.0 & 14.8 & 12.5 \\
\hline $908(106-1191)$ & 39 & $M$ & 76.4 & 13.8 & 3.7 & 7.6 & 0.7 & 36.7 & 8.9 & 9.8 \\
\hline B & & W & 78.1 & 11.8 & 4.6 & 7.0 & 1.0 & 31.4 & 14.1 & 12.3 \\
\hline 1705 (1208-2067) & 24 & $M$ & 76.6 & 13.1 & 3.9 & 7.7 & 0.5 & 37.3 & 9.7 & 9.6 \\
\hline $\mathrm{C}$ & & W & 77.8 & 10.0 & 5.4 & 7.0 & 1.0 & 31.7 & 13.1 & 12.5 \\
\hline $2481(2098-3981)$ & 17 & M & 76.3 & 11.7 & 5.0 & 9.0 & 0.4 & 35.9 & 8.7 & 9.8 \\
\hline $\mathrm{D}$ & & $\mathrm{W}$ & 77.7 & 9.6 & 4.7 & 7.1 & 0.7 & 27.4 & 13.7 & 8.8 \\
\hline $5580(3984-7309)$ & 10 & $M$ & 76.0 & 10.7 & 4.0 & 8.3 & 0.4 & 33.2 & 7.9 & 7.7 \\
\hline
\end{tabular}

${ }^{\star}$ Number of patients of all ages with primary or secondary hospitalisation for heart failure from 1992-1995. $\dagger$ Previous endocrinal, nutritional, and metabolic diseases, or immunity disorders. W: women, M: men.

variance in prognosis that was explained by institutional factors (that is, the intra-hospital correlation) were used as measures of hospital effects. Intra-hospital correlation was calculated as 2 nd level variance/(2nd level variance $\left.+\pi^{2} / 3\right)$ as indicated by Snijders. ${ }^{10}$

To illustrate hospital differences in prognosis, they were ranked by logarithm odds ratios having the whole country of Sweden as reference (value $=0$ ), and uncertainty was estimated by $95 \%$ confidence intervals (that is, level 2 residuals $+/-1.96 \mathrm{SE})$. Individual odds ratios (95\% confidence intervals) were obtained from the $\beta$ coefficient (standard error) in the fixed part of the model. Parameters were estimated using Iterative Generalized Least Square (IGLS) and Markov Chain Monte Carlo (MCMC). ${ }^{11}$ The MLwiN, Version 1.1, software package was used to perform the analyses. ${ }^{11}$
Kaplan-Meier curves ${ }^{12}$ were used for graphical presentation of national 30 day survival rates in men and in women. Follow up time was calculated from date of admission until death, or until a period of 30 days had elapsed.

\section{Results}

CHARACTERISTICS OF THE POPULATION

The age of the patients ranged from 65 to 85 years, with a mean of 78 years for women and 76 years for men (age distribution is shown in figure 1). Of 38343 patients, a total of 4466 died within a 30 day period after admission: $10.9 \%$ of the women (1946/17 923), and $12.3 \%$ of the men $(2520 / 20420)$. The nationwide 30 day survival curve showed greater mortality in men than in women (fig 2). Mortality statistics of these 4466 patients are presented in table 1. Cardiovascular disease

Table 3 Odds ratios (OR) and 95\% confidence intervals (95\% CI) of 30 day mortality after first time hospitalisation for heart failure from 1992 to 1995; and hospital contextual effects (that is, 2nd level variance and intra-hospital correlation) in 27786 men from 90 Swedish acute care hospitals with regard to age, previous disease, and hospital size

\begin{tabular}{|c|c|c|c|}
\hline & \multirow[b]{2}{*}{ Individual effects } & \multicolumn{2}{|l|}{ Hospital effects } \\
\hline & & 2 nd level variance $(95 \%$ CI) & $\begin{array}{l}\text { Intra-hospital } \\
\text { correlation }\end{array}$ \\
\hline \multicolumn{4}{|l|}{ Model 1 (empty) } \\
\hline & OR $(95 \% \mathrm{CI})$ & $0.053(0.025,0.082)$ & $1.6 \%$ \\
\hline \multicolumn{4}{|l|}{ Model 2} \\
\hline \multicolumn{4}{|l|}{ Age } \\
\hline $65-69$ & Reference & $0.053(0.025,0.082)$ & \\
\hline $70-79$ & $1.41(1.21,1.64)$ & $(0.0 \%) \dagger$ & \\
\hline $80-85$ & $2.25(1.94,2.62)$ & & \\
\hline \multicolumn{4}{|l|}{ Model 3 (age adjusted) } \\
\hline Cardiovascular disease (yes/no) & $0.98(0.89,1.07)$ & & \\
\hline Cancer (yes/no) & $1.39(1.21,1.60)$ & & \\
\hline Infectious disease (yes/no) & $1.25(1.02,1.52)$ & $0.056(0.026,0.084)$ & \\
\hline Senile dementia (yes/no) & $3.32(2.17,5.08)$ & $(+5.7 \%) \dagger$ & \\
\hline Injuries and intoxications (yes/no) & $1.17(1.02,1.35)$ & & \\
\hline Other diseases $\ddagger$ (yes/no) & $1.30(1.12,1.50)$ & & \\
\hline \multicolumn{4}{|l|}{ Model 4 (age adjusted) } \\
\hline \multicolumn{4}{|l|}{ Hospital size (see table 2) } \\
\hline Group D & Reference & & \\
\hline Group C & $1.08(0.88,1.33)$ & $0.041(0.016,0.066)$ & \\
\hline Group B & $1.22(1.00,1.48)$ & $(-22.6 \%) \dagger$ & \\
\hline Group A & $1.30(1.07,1.57)$ & & \\
\hline \multicolumn{4}{|l|}{ Model 5 (age adjusted) } \\
\hline Cardiovascular disease (yes/no) & $0.97(0.89,1.07)$ & & \\
\hline Cancer (yes/no) & $1.39(1.21,1.60)$ & & \\
\hline Infectious disease (yes/no) & $1.25(1.03,1.52)$ & & \\
\hline Senile dementia (yes/no) & $3.28(2.00,5.40)$ & & \\
\hline Injuries and intoxications (yes/no) & $1.17(1.02,1.35)$ & $0.044(0.016,0.066)$ & \\
\hline Other diseases $\ddagger$ (yes/no) & $1.29(1.12,1.49)$ & $(-17.0 \%) \dagger$ & \\
\hline \multicolumn{4}{|l|}{ Hospital size (see table 2) } \\
\hline D group & Reference & & \\
\hline C group & $1.07(0.88,1.33)$ & & \\
\hline B group & $1.22(1.00,1.48)$ & & \\
\hline A group & $1.30(1.07,1.57)$ & & \\
\hline
\end{tabular}

*Percentage of total variance in 30 day mortality related to hospital factors. †Percentage of the between hospital variance explained by the added variables. $¥$ Previous endocrinological, nutritional, metabolic diseases, or immunity disorders. 
Table 4 Odds ratios (OR) and 95\% confidence intervals (95\% CI) of 30 day mortality after first time hospitalisation for heart failure from 1992 to 1995; and hospital contextual effects (that is, 2nd level variance and intra-hospital correlation) in 17923 women from 90 Swedish hospitals with regard to age, previous diseases, and hospital size

\begin{tabular}{|c|c|c|c|}
\hline & \multirow[b]{2}{*}{ Individual effects } & \multicolumn{2}{|l|}{ Hospital effects } \\
\hline & & 2nd level variance $(95 \%$ CI) & $\begin{array}{l}\text { Intra-hospital } \\
\text { correlation }\end{array}$ \\
\hline \multicolumn{4}{|l|}{ Model 1 (empty) } \\
\hline & & $0.078(0.038,0.118)$ & $2.3 \%$ \\
\hline \multicolumn{4}{|l|}{ Model 2} \\
\hline \multicolumn{4}{|l|}{ Age } \\
\hline $65-69$ & Reference & $0.078(0.038,0.119)$ & \\
\hline $70-79$ & $1.39(1.13,1.72)$ & $(0.0 \%) \dagger$ & \\
\hline $80-85$ & $1.98(1.61,2.43)$ & & \\
\hline \multicolumn{4}{|l|}{ Model 3 (age adjusted) } \\
\hline Cardiovascular disease (yes/no) & $0.93(0.84,1.04)$ & & \\
\hline Cancer (yes/no) & $1.15(0.96,1.37)$ & & \\
\hline Infectious disease (yes/no) & $1.18(0.96,1.46)$ & $0.075(0.037,0.116)$ & \\
\hline Senile dementia (yes/no) & $3.68(2.81,4.83)$ & $(-4.0 \%) \dagger$ & \\
\hline Injuries and intoxications (yes/no) & $1.25(1.10,1.42)$ & & \\
\hline Other diseases $\ddagger$ (yes/no) & $1.30(1.12,1.51)$ & & \\
\hline \multicolumn{4}{|l|}{ Model 4 (age adjusted) } \\
\hline \multicolumn{4}{|l|}{ Hospital size (see table 2) } \\
\hline Group D & Reference & & \\
\hline Group C & $1.01(0.79,1.30)$ & $0.066(0.030,0.103)$ & \\
\hline Group B & $1.20(0.94,1.52)$ & $(-15.4 \%) \dagger$ & \\
\hline Group A & $1.24(0.99,1.56)$ & & \\
\hline \multicolumn{4}{|l|}{ Model 5 (age adjusted) } \\
\hline Cardiovascular disease (yes/no) & $0.93(0.84,1.04)$ & & \\
\hline Cancer (yes/no) & $1.15(0.96,1.37)$ & & \\
\hline Infectious disease (yes/no) & $1.19(1.96,1.46)$ & & \\
\hline Senile dementia (yes/no) & $3.68(2.61,5.19)$ & & \\
\hline Injuries and intoxications (yes/no) & $1.26(1.11,1.44)$ & $0.065(0.030,0.101)$ & \\
\hline Other diseases $\ddagger$ (yes/no) & $1.30(1.12,1.50)$ & $(-16.7 \%) \dagger$ & \\
\hline \multicolumn{4}{|l|}{ Hospital size (see table 2) } \\
\hline Group D & Reference & & \\
\hline Group C & $1.00(0.78,1.28)$ & & \\
\hline Group B & $1.18(0.94,1.49)$ & & \\
\hline Group A & $1.23(0.98,1.54)$ & & \\
\hline
\end{tabular}

*Percentage of total variance in 30 day mortality related to hospital factor. †Percentage of the between hospital variance explained by the added variables. $¥$ Previous endocrinological, nutritional, metabolic diseases and immunity disorders.

was the most frequent cause of death, with three diagnoses (chronic ischaemic heart disease, acute myocardial infarction, and heart failure) accounting for about $53 \%$ of the cases. Nine other conditions caused the deaths of $21 \%$ of the patients (arteriosclerosis, valve disorder, complications of heart disease, old myocardial infarction, arrhythmias, pulmonary embolism and infarction, stroke, pneumonia, and diabetes mellitus).

One quarter of all patients in the survey were treated at the 10 largest acute care hospitals in Sweden (table 2, Group D), and a second quarter were inpatients at the 39 smallest such facilities (table 2, Group A). The larger institutions seemed to present slight lower prevalences of senile dementia, cardiovascular disease, endocrinological, nutritional, metabolic or immunological disease, and prior injuries and intoxications. In contrast, the prevalence of cancer seemed to be slightly higher in men. The data showed that the short-term prognosis of both men and women in hospitals with fewer patients (Groups A and B) was worse than in the largest institutions (Groups C and D).

INDIVIDUAL DETERMINANTS OF PROGNOSIS Individual age was a strong determinant of impaired prognosis in both men and women. Previous cancer, infectious disease, and endocrinological, nutritional, metabolical or immunological diseases were obvious determinants of 30 day mortality-particularly for men. Injury or intoxication contributed to an impaired prognosis for women, although not for men. Previous hospitalisation for senile dementia was also clearly associated with increased 30 day mortality.

These individual risk estimations proved very similar when all the studied variables were entered into the model (tables 3 and 4).

HOSPITAL DETERMINANTS OF PROGNOSIS

In the empty multilevel model, the intrahospital correlation showed that $1.6 \%$ (men) and $2.3 \%$ (women) of the national variance in prognosis was related to either compositional or contextual hospital factors (tables 3 and 4). The empty multilevel model showed a small but significant between hospital variance in 30 day mortality; both for men $(0.053,95 \% \mathrm{CI}$ : $0.025,0.082)$ and women $(0.078,95 \% \mathrm{CI}$ : $0.038,0.118$ ), and this variance was unchanged when controlling for the age of the patients (Model 2). Adjustment for age and other diseases (Model 3) slightly increased the between hospital variance in men $(+5.7 \%)$ but reduced this variance by $-4 \%$ in women. The contextual variable (that is, hospital size) reduced the age adjusted between hospital variance by $22.6 \%$ (men) and $15.4 \%$ (women), and evidence of hospital effects remained after adjusting for all variables studied (Model 5).

Hospital size presented a dose response association with individual 30 day mortality (that is, the fewer the patients, the worse the individual prognosis). 


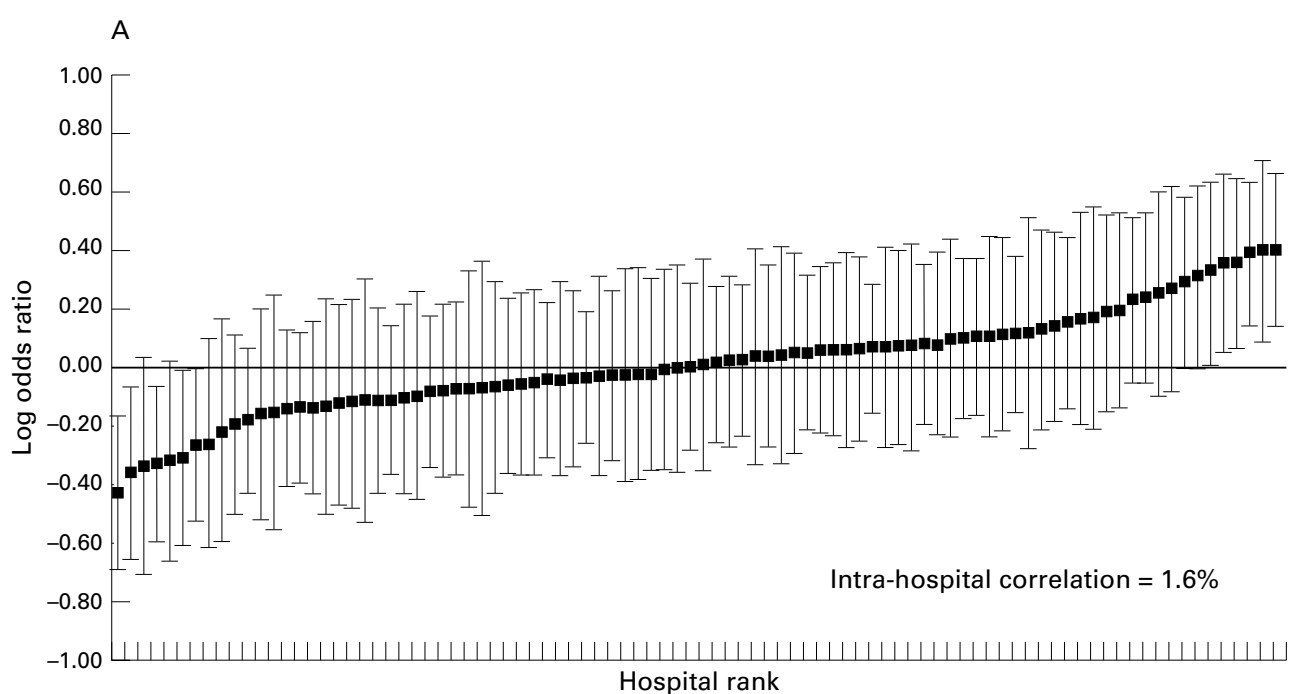

B

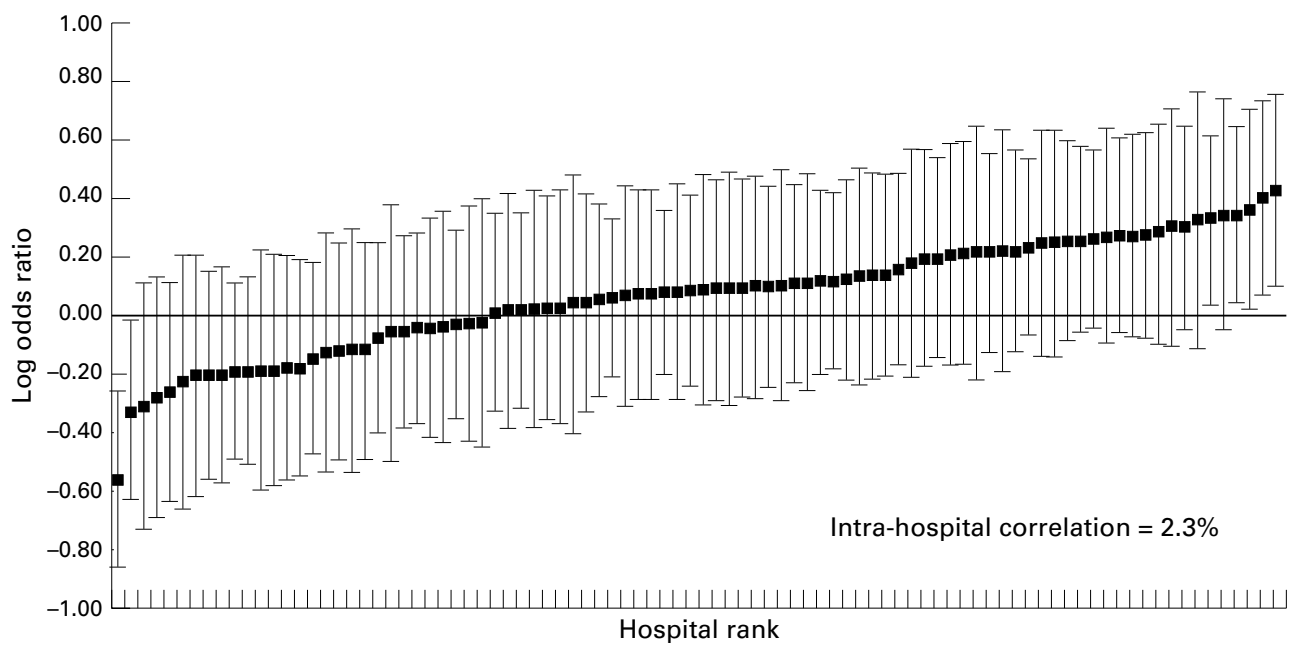

Figure 3 Inter-hospital differences in short-term prognosis (that is, 30 day mortality) after initial hospitalisation for heart failure in 90 Swedish acute care hospitals (1992-1995). National mean = zero. Values are logarithm odds ratios adjusted for individual age and previous hospitalisation for other diseases. The vertical lines represent $95 \%$ confidence intervals. (A) Men, (B) women.

RANKING OF THE HOSPITALS

In the case of men, five of the hospitals presented a significantly better, and seven a significantly worse, outcome than the mean in Sweden (fig 3A). For women, two hospitals had a better, and five had a worse outcome than the Swedish mean (fig 3B). However, none of these hospitals could be distinguished with certainty from other institutions at the opposite end (most distal centiles) of the spectrum. In fact, most hospitals in our study had similar outcomes and could not be placed with certainty at any specific point in the range.

\section{Discussion}

The present multilevel analysis revealed that national variation in short-term prognosis after an initial hospitalisation for heart failure was mainly explained by individual differences between patients. Hospital factors only accounted for a modest proportion of the national variation $(1.6 \%$ in men and $2.3 \%$ in women). Nevertheless, when comparing institutions, short-term prognoses seemed to be better in patients treated at the largest hospitals (that is, the greater the number of patients in the institution, the better the individual prognosis).

On the other hand, it is also possible that the variables used for adjustment of compositional factors (that is, age and prior hospitalisations for other diseases) did not completely measure the severity of the patients. ${ }^{13}$ Compositional residual confounding could, therefore, explain the hospital effect found. However, further analyses using secondary or other diagnoses at the time of admission for a primary diagnosis of heart failure-rather than previous diagnoses-did not reduce the inter-hospital differences for 30 day mortality (not shown in the tables). Information on comorbidity was appraised by means of previous hospitalisations, as recorded in the National Patient Register. We recognise that patients in various hospitals may have many differences, aside from their history of prior hospitalisations. In any case, individual residual confounding may have overestimated rather than underestimated the small institutional effects found. 
To study the influence of hospital practice on short-term prognosis, we chose to analyse mortality within a 30 day period after admission, rather than focusing on intra-hospital mortality, as some hospitals may tend to discharge terminal patients earlier than others, and this fact might possibly have introduced bias. $^{13}$

In this study comprising all the patients in Sweden, mortality after heart failure was higher than that reported in clinical trials. ${ }^{14}$ On the other hand, our results were in agreement with previous population-based survival analyses from Scotland.$^{15}$ It is known that many patients are not included in clinical trials because they are considered at high risk, ${ }^{16}$ a factor that seems to reduce the external validity of clinical trials regarding estimations of survival after heart failure in the general population.

Our study was limited to patients whose principal diagnosis was heart failure. These diagnoses, however, were not validated, ${ }^{17}$ and this, in theory, may have introduced differential institutional information bias in cases where diagnostic practices varied among hospitals. This phenomenon has recently been noted for myocardial infarction diagnosis. ${ }^{18}$ Control for this bias may possibly have reduced hospital effects even further.

It is also important to consider that patients living near to a hospital may seek hospital care for less severe instances of heart failure than patients living far from one. Such a selection bias would help explain the better prognosis attributed to some large hospitals by the data. On the other hand, the capacity to admit a great number of patients may indicate the availability of improved care facilities. It must also be recalled that larger institutions tend to be teaching hospitals. These factors in themselves may influence individual prognosis in a positive way.

\section{RANKING OF HOSPITALS}

The aim of our study was to disentangle individual (patient) factors from institutional (hospital) ones in explaining variation in prognosis after an initial heart failure hospitalisation in Sweden-not to rank hospitals. However, multilevel analysis allows a more appropriate understanding of uncertainty when ranking hospitals than conventional analytical methods do. ${ }^{3}$ Moreover, as our analysis was based on a four year period (1992-1995) and on a very large study population, it reduced random fluctuation in the incidence of hospitalisations for heart failure. On this basis, we found that most hospitals could not be placed with certainty at any specific position within the range. The few hospitals where 30 day mortality was noticeably lower or higher than the Swedish mean were not otherwise distinguishable from most hospitals.

In addition, the size of the hospital effect in both men and women was rather small, and it is within this general effect that relatively large differences between hospitals (that is, log odds ratio values in figure 3 ) need to be interpreted. At this point, therefore, it would be misleading
KEY POINTS

- Accurate epidemiological monitoring is desirable to understand inequality in the prognosis of heart failure.

- Single level analyses lead to inappropriate results, which mislead public opinion and provide an unsuitable basis for decision making.

- Multilevel analysis is considered today a more appropriate way to monitor health care performance.

- National variation in short-term prognosis after heart failure was mainly explained by differences between patients, with hospital factors playing a minor part.

- Hospital size seemed to emerge as one determinant of short-term prognosis after heart failure (that is, the greater the number of patients, the better the individual prognosis).

to categorically assert that patients have a better prognosis at some hospitals than others.

INDIVIDUAL DETERMINANTS OF PROGNOSIS As could be expected, age, as well as previous cancers, previous infectious disease, previous injury and intoxication, and previous endocrinological, nutritional, metabolical or immunological disease were clear individual determinants of prognosis (tables 3 and 4); the same was true for secondary diagnoses at the time of admission for a primary diagnosis of heart failure (not shown in the tables). The individual odds ratios (95\% CI) of 30 day mortality in relation to coexisting cardiovascular diseases were $1.28(1.17,1.40)$ and 1.20 $(1.09,1.32)$ in men and in women, respectively. These odds ratios were $3.43(2.99,3.93)$ and $2.42(2.00,2.93)$ for cancer; $2.41(1.84$, $3.17)$ and $1.33(0.96,1.84)$ for infectious disease; and $2.47(1.82,3.35)$ in men and 1.93 $(1.42,2.63)$ in women for coexisting injuries and intoxications. However, the mechanism underlying the strong association between 30 day mortality and previous (tables 3 and 4), as well as coexisting dementia, $2.97(2.20,3.99)$ in men and $2.08(1.54,2.81)$ in women, is more elusive. It may be a consequence of impaired patient management because a patient's prognosis after heart failure is very dependent on carefully following a treatment regimen. The care regimen must itself be continuously adapted to the unstable clinical conditions of the patient. In this regard, patient education concerning the nature of the condition, as well as collaboration between the patient and the medical team, plays a definite part ${ }^{19}$ - one which is certainly hindered by impaired cognitive capacity. Finally, the prognosis of patients with senile dementia might also be influenced by adverse drug reactions, as many such patients are treated with drugs (for example, neuroleptics) known to impair heart functioning. ${ }^{20}$

In conclusion, our investigation found that national variation in short-term prognosis (that is, 30 day mortality) after initial hospitalisation 
for heart failure was mainly explained by individual patient variation. Consequently, the prognosis of a specific patient was only marginally influenced by the particular hospital to which the patient was admitted. Nevertheless, hospital factors did show a modest but statistically discernable effect on the observed differences in prognosis, with hospital size (that is, the larger the facility, the better the individual prognosis) appearing to be one determinant.

We express our gratitude to the Swedish Centre for Epidemiology, to the reference group Active Analysis at the County of Skåne, to Alastair Leyland (MRC Social and Public Health Services Unit, University of Glasgow) and to Min Yang (Multilevel Models Project, Institute of Education, London).

Funding: this study was supported by the NEPI Foundation; an ALF-Government Grant (Dnr M: E 39 390/98, Dr. Juan Merlo), and by the National Institute for Public Health.

Conflicts of interest: none.

1 Haldeman GA, Croft JB, Giles WH, et al. Hospitalization of patients with heart failure: National Hospital Discharge Survey, 1985 to 1995. Am Heart F 1999;137:352-60.

2 Equity in health - a second step towards national goals in public health. [In Swedish]. Considerations from the Governmen Commission on National Public Health. Statens offentliga utredningar. Stockholm: SOU, 1999. Report nr 137.

3 Goldstein H, Spiegelhalter DJ. League tables and their limitations: statistical issues in comparisons of institutional performance Fournal of the Royal Statistical Society, ser A 1996;159:385-443

4 Marshall EC, Spiegelhalter DJ. Reliability of league tables of in vitro fertilisation clinics: retrospective analysis of live birth rates. BMF 1998;316:1701-4.

5 Parry GJ, Gould CR, McCabe CJ, et al. Annual league tables of mortality in neonatal intensive care units: longitudinal study. BMF 1998;316:1931-5.
6 Leyland A, Boddy A. League tables and acute myocardial infarction. Lancet 1998;351:555-8.

7 Rice N, Leyland A. Multilevel models: applications to health data. $\mathcal{F}$ Health Serv Res Policy 1996;3:154-64.

8 Duncan C, Jones K, Moon G. Context, composition and heterogeneity: using multilevel models in health research. Soc Sci Med 1998;46:97-117.

9 Merlo J, Lindblad U, Pessah-Rasmussen H, et al. Comparison of different procedures to identify probable cases of myocardial infarction and stroke in two Swedish prospective cohort studies using local and national routine registers. Eur 7 Epidemiol 2000;16:235-43

10 Snijders TAB, Bosker, RJ. Multilevel analysis: an introduction to basic and advanced multilevel modeling. London: Sage Publishers, 1999.

11 Rasbash J, Browne W, Goldstein $\mathrm{H}$, et al. A user's guide to $M L w i N$. London: Institute of Education, 1999

12 Kaplan EL, Meier P. Nonparametric estimation from incomplete observations. $\mathcal{F}$ Am Stat Assoc 1958;53:457-81.

3 Iezzoni L. Using risk-adjusted outcomes to assess clinical practice: an overview of issues pertaining to risk adjustment. Ann Thorac Surg 1994;58:1822-6.

14 Cleland JFG. Clinical trials in heart failure. In: Julian DG, Pitt B, eds. Clinical trials in cardiology. London: Saunders, 1997:309-54.

15 Cleland JGF, Gemmell I, Khand A, et al. Is the prognosis of heart failure improving?. Eur $\mathcal{F}$ Heart Failure 1999;1:22941

16 Kober L, Torp-Pedersen C. Clinical characteristics and mortality of patients screened for entry into the Trandolmortality of patients screened for entry into the Trandolapril Cardiac

17 Goff DC Jr, Pandey DK, Chan FA, et al. Congestive heart failure in the United States: is there more than meets the (CD code)? The Corpus Christi Heart Project. Arch Intern Med 2000;160:197-202.

18 Evaluations of the quality of the diagnosis of acute myocardial infarction in the Patient Register 1985 and 1995. [In Swedish]. Stockholm: Centre for Epidemiology at the National Board of Health and Welfare, 2000.

19 Björck-Linné A, Liedholm H, Israelsson B. Effects of systematic education on heart failure patients' knowledge after 6 months: a rondomised, controlled trial. Eur $\mathcal{F}$ Heart Failure 1999;1:219-27.

20 Vrobel TR. Psychiatric aspects of congestive heart failure: implications for consulting psychiatrists. Int $\mathcal{F}$ Psychiatry Med 1989;19:211-25.

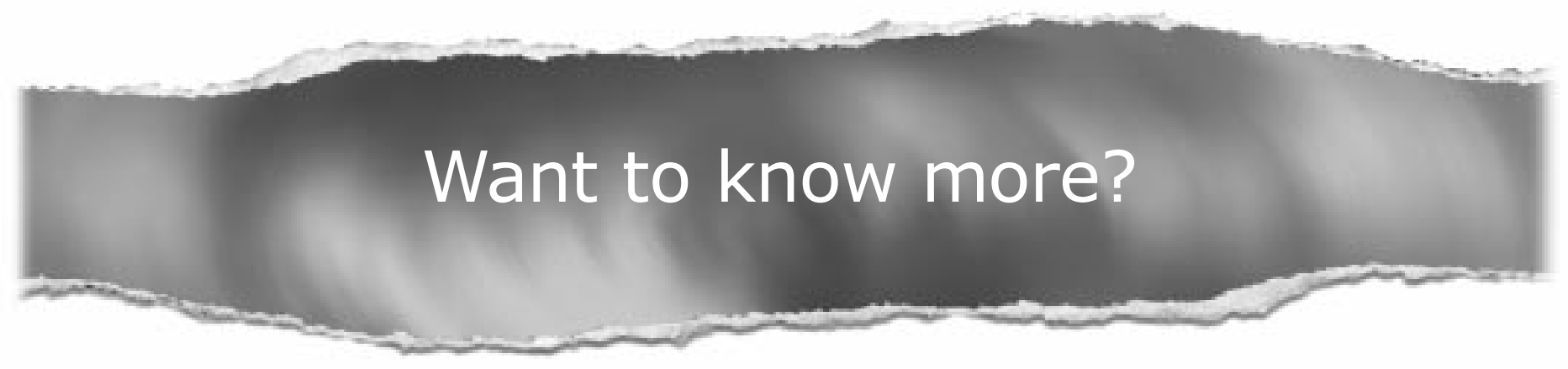

Data supplements

Limited space in printed journals means that interesting data and other material are often edited out of articles; however, limitless cyberspace means that we can include this information online. Look out for additional tables, references, illustrations. 